\title{
Study on Film Drip Irrigation of Maize to Dynamic Changes of Soil Temperature
}

\author{
Zeyu Liu ${ }^{12}$, Yong Wang ${ }^{1}$, Zhou Yu ${ }^{12}$, Xing Li ${ }^{1}$, Dihan Luo ${ }^{12}$ \\ (1.Inner Mongolia Water-saving Agricultural Engineering Research Center, Inner Mongolia Normal University, Hohhot, 010022, China; 2. \\ College of Geographical Sciences, Inner Mongolia Normal University, Hohhot, 010022, China)
}

\begin{abstract}
On the observation data of maize under film drip irrigation in different depth of soil temperature and air temperature, analyzed the change status of film mulching and no film mulching field maize at different depths temperature, the study of the dynamic changes of soil temperature in different growth stages, and the effects of irrigation on soil temperature, at the same time for the soil temperature under different weather conditions were compared. The results showed that: (1) in the early stage of the experiment, there are obvious differences film mulching and no film mulching soil temperature, but existed a smaller temperature differential with air temperature; the later period of the experiment, the soil temperature field mulching and no film mulching began to close, the temperature difference is small, but existed a significant difference between air temperature and soil temperature, the maximum temperature difference of $6^{\circ} \mathrm{C}$. (2) Before irrigation, soil temperature mainly affected by air temperature, with the irrigation time, irrigation affected by soil temperature in the vertical direction, with the moisture infiltration, the temperature of each soil layer decreased gradually, $0 \sim 20 \mathrm{~cm}$ soil layer temperature was positively related to soil depth, temperature values expressed as $5 \mathrm{~cm}>10 \mathrm{~cm}>15 \mathrm{~cm}>20 \mathrm{~cm}$.(3) Before jointing maize soil warming effect is obvious, after jointing warming effect is not obvious, as the soil depth deepened even lower. (4) Different weather conditions on the film corn soil temperature differential impact, characterized by sunny day $>$ cloudy $>$ overcast sky $>$ rainy day.
\end{abstract}

\section{Introduction}

Drip irrigation technology is covered mulching and drip irrigation technology measures the combination of a new technology that can improve soil moisture, heat, gas and other characteristics [1]. Mulching with a warming, soil moisture, precocious, production, prevent soil erosion, and control soil salinity, reducing nitrogen leaching and so on. Drip irrigation has water, fertilizer, labor, control of temperature and humidity, maintain soil structure, improve quality, and increase efficiency and so on. In arid and semi-arid areas in northern China has been widely used, has become an important agricultural production and technical measures [2-5]. Plastic film is a heat balance on soil most obvious material. Soil surface covered with a thin film, compared to non-covered surface net radiation falling incomes, sensible heat exchange weakened, latent heat exchange tends to zero. There are films with no film and film number, depth, time and so affect the ground temperature changes. The case of film, the transmission and the barrier effect of the film and the film surface temperature hysteresis of water droplets condense on the way and will greatly affect the rate of heat conduction, the temperature change will be different from the case of the film is not covered, ground temperature distribution film with depth and time will become more complicated [6-7]. Drip Irrigation under water can be timely and appropriate manner for fertilizer to the crop root zone, adjust the temperature and humidity between trees; at the same time when mulching diurnal temperature variation, film condensation, can improve crop growth of micro-climate, which provides for crop growth good condition [8].

Irrigation under technology scholars launched a number of studies [9-10], in terms of water and heat, drip irrigation under the ground temperature in time and space showing a special distribution [11], scholars in the study to get some conclusions: In the film conditions, hydrothermal conditions in cotton soil improvement, crop germination rate, growth conditions, and the final yield has greatly improved [12-13]; under Drip Irrigation, root zone hydrothermal conditions have been significantly improved, the ground temperature changes with temperature changes with increasing depth, amplitude gradually gentle, and accompanied by the lagged effects [14-19].

In order to better understand the impact of film drip irrigation systems on soil temperature, in this paper, Nanpingfang Village, Dangpudi town, Songshan District, Chifeng city Hilly land as an example, the choice of the current production representative, to promote the application of larger "a plastic film, a drip irrigation pipe, and two corn rows" planting pattern patterns in the range $0 \sim 20 \mathrm{~cm}$ soil layer were divided four growth period soil temperature monitoring system to study the variation of Drip Irrigation under maize rhizosphere soil temperature at the location of the different analyzes the different stages of soil fertility dynamic changes in temperature, irrigation on corn in different soil temperatures, and the effects of different weather conditions on corn soil temperature, water consumption and to explore the mechanism of film drip corn yield provide a theoretical basis.

\section{Materials and methods}

\subsection{Study area}

Test in 2013 from May to October in Nanpingfang Village, Dangpudi town, Songshan District, Chifeng city, Inner Mongolia Autonomous Region, $\left(118^{\circ} 53^{\prime} 18.53^{\prime \prime} \mathrm{E}\right.$, $42^{\circ} 24^{\prime} 53.50^{\prime \prime} \mathrm{N}$ ), elevation of $679 \mathrm{~m}$. Texture is sandy loam soil, the field capacity of $1 \mathrm{~m}$ deep soil layer is $21.86 \%$ (mass water content), the average soil dry bulk density 
$1.39 \mathrm{~g} / \mathrm{cm}^{3}$, Alkali hydrolysable nitrogen $27 \mathrm{mg} / \mathrm{kg}$, Available phosphorus $0.8 \mathrm{mg} / \mathrm{kg}$, available $\mathrm{k} 100 \mathrm{mg} / \mathrm{kg}$, and organic matter content $7.4 \mathrm{~g} / \mathrm{kg}, \mathrm{pH}$ value is 8.3 . The annual average precipitation $365 \mathrm{~mm}$, in 2013 the growth period of rainfall of $309 \mathrm{~mm}$, accounted for $78.19 \%$ of precipitation, which belongs to the flat water years. Annual sunshine 2800 3000h, frost free period 115 145d.

\subsection{Experimental design}

Experiments using field plot test, experimental plot of corn adopt "a plastic film, a drip irrigation pipe, and two corn rows" planting pattern. Using both the size of the ridge of double cropping patterns, drip irrigation belt along the direction of crop planting single line layout, planting spacing is $40 \mathrm{~cm}$, line spacing (big ridge) $80 \mathrm{~cm}$, corn plant spacing $21 \sim 23 \mathrm{~cm}$, drip irrigation tape spacing $120 \mathrm{~cm}$, film thickness $0.008 \mathrm{~mm}$, emitter flow $2 \mathrm{~L} / \mathrm{h}$. Sowing time is May 5, 2013, tested crops 'Xianyu335' American Pioneer corn hybrids bred, the sowing quantity of $45 \sim 60 \mathrm{~kg}$ per hectare, about $72000 \sim 79500$ corn plants per hectare. Maize on 2-3 October harvest, growth period $152 \mathrm{~d}$, is divided into five periods, namely seedling, jointing, heading, filling and maturity stage.

Experimental plot of corn adopt "a plastic film, a drip irrigation pipe, and two corn rows" planting pattern. Using both the size of the ridge of double cropping patterns, drip irrigation belt along the direction of crop planting single line layout, planting spacing is $40 \mathrm{~cm}$, line spacing (big ridge) $80 \mathrm{~cm}$, corn plant spacing $21 \sim 23 \mathrm{~cm}$, drip irrigation tape spacing $120 \mathrm{~cm}$, film thickness $0.008 \mathrm{~mm}$, emitter flow 2L/h. Sowing time is May 5, 2013, the sowing quantity of $45 \sim 60 \mathrm{~kg}$ per hectare, about 72000 79500 corn plants per hectare.

Sowing fertilizing amount by $\mathrm{N} 375 \mathrm{~kg} / \mathrm{hm}^{2}$, P2O5 $270 \mathrm{~kg} / \mathrm{hm}^{2}, \mathrm{~K} 2 \mathrm{O} 225 \mathrm{~kg} / \mathrm{hm}^{2}$, fertilization mode for mechanical fertilization 10 20cm.In October 3, 2013, Maize harvest, corn whole growth period of $152 \mathrm{~d}$.

\subsection{Method}

Experimental treatments for film mulching and no film mulching drip irrigation, in the middle of the film (from the maize plant about $20 \mathrm{~cm}$ ) and the outer membrane $(20 \mathrm{~cm}$ away from the maize plant) laid observation point, the observation of soil depth of $20 \mathrm{~cm}$, every $5 \mathrm{~cm}$ install a mercury thermometer. Since the emergence to harvest, soil temperature observations twice a day, 08:00 and 14: 00 , repeat 2 times, and record the weather conditions that day.

Meteorological data from local weather station data.

\section{Results}

\subsection{Film Drip maize field soil temperature changes in different soil layer}

2013 experimental plots with different soil depth temperature variations days after corn planting are shown in Figure 1. Figure 1 shows that, in the early growth stage of corn (the first 7-42 days after sowing), film mulching and no film mulching different soil depth temperatures with the air temperature change, but it is small differential with the air temperature; late growth stage (after sowing 42-84 days), film mulching and no film mulching different soil depth temperatures with the air temperature exists obvious difference, the maximum difference of $6^{\circ} \mathrm{C}$.

In the early growth stage of maize, film mulching and no film mulching different soil depth temperature difference is obvious; late growth stage, film mulching and no film mulching soil temperature gradually closer, to after sowing the 84 days, basically no significant difference; thus shows that in the early stage of film can effectively improve and maintain soil temperature, over time, to the late film improve and maintain soil temperature effect begins to decrease.

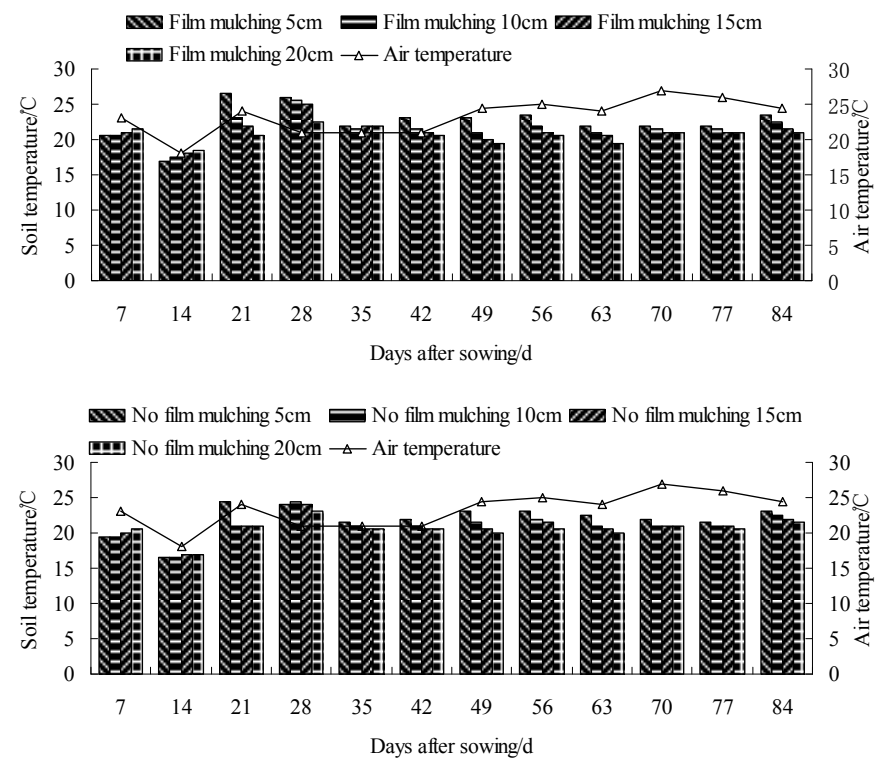

Figure.1: Covered and uncovered in different soil depth temperature contrast 


\subsection{Effects of irrigation on soil temperature of different soil layer in film drip maize field}

In August 2013 13-16 Data Analysis irrigation (irrigation water temperature is $15^{\circ} \mathrm{C}$ ) effects on different soil depth temperature (see Figure 2).Before irrigation soil temperature is mainly influenced by air temperature, over time of irrigation, soil temperature is in the vertical direction with soil moisture infiltration each soil layer gradually decreased, $0 \sim 20 \mathrm{~cm}$ soil depth temperature and a positive correlation, the temperature value
$5 \mathrm{~cm}>10 \mathrm{~cm}>15 \mathrm{~cm}>20 \mathrm{~cm}$, while the soil temperature is affected by diminishing water decreased. Increased with soil depth temperature hysteresis phenomenon is more obvious, mainly because is deep soil less interference by external factors, soil temperature mainly affected by the air temperature and irrigation, and irrigation water infiltration temporal existence, which led to temperature change

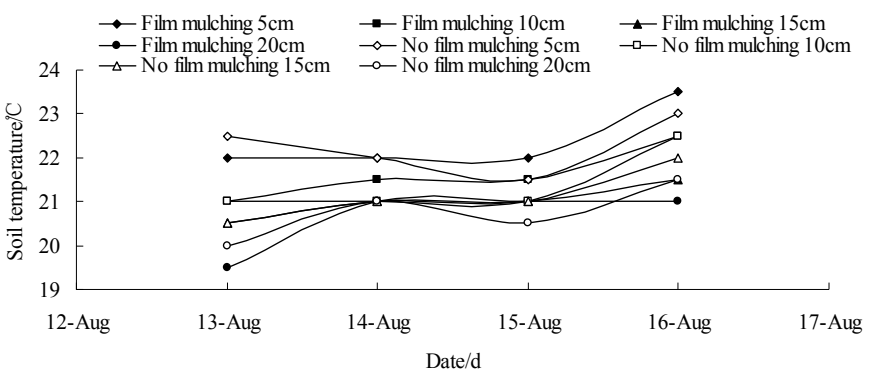

Figure.2: Effects of irrigation on soil temperature

\subsection{The dynamic changes of soil temperature in different growth stages}

Each growth period film mulching and no film mulching soil temperature decreases with the magnitude of delayed childbearing, seedling biggest change, the most significant reach $1.25^{\circ} \mathrm{C}$, the average change in the magnitude of $1^{\circ} \mathrm{C}$, filling the magnitude of change min. Daily variation margin was mainly caused by changes in atmospheric temperature; the larger the temperature difference between day and night seedling stages, over time, with the air temperature drops day and night temperature decreases, therefore, seedling stage soil temperature the amplitude of variation maximum. Soil temperature in two growth stages before maize is always film mulching greater than no film mulching, but after jointing stage of this situation has changed, film mulching and no film mulching soil temperature difference is small.
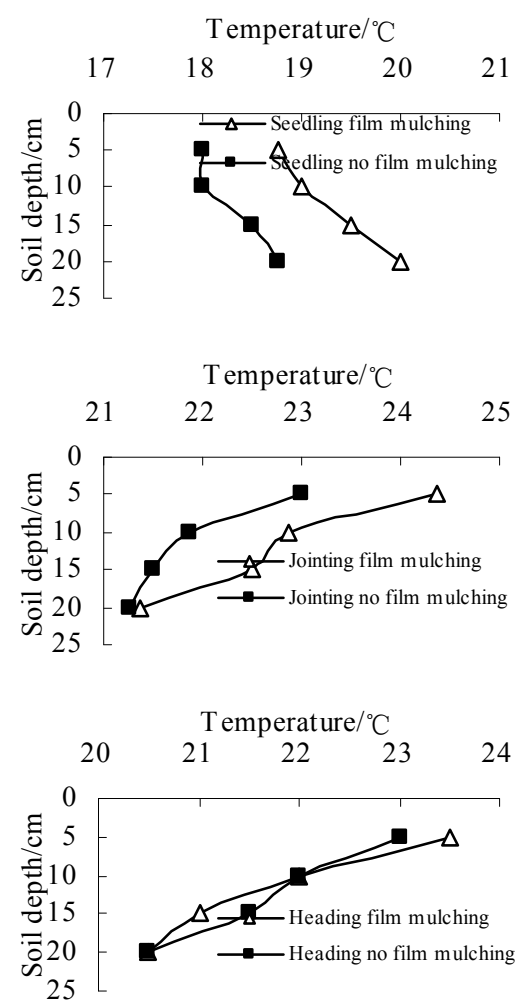

Temperature $/{ }^{\circ} \mathrm{C}$
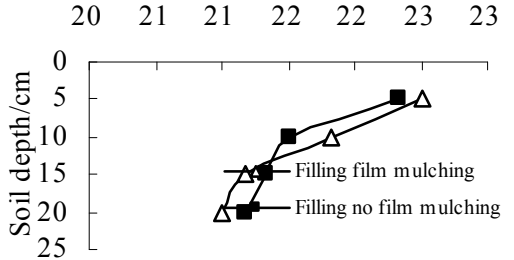

Figure.3: Change of soil temperature in different growth stages 
In seedling soil temperature film mulching than no film mulching on average low $1{ }^{\circ} \mathrm{C}$, and $20 \mathrm{~cm}>15 \mathrm{~cm}>10 \mathrm{~cm}>5 \mathrm{~cm}$ at the temperature, and in the jointing stage showed the opposite tendency, namely at different depths soil temperature $5 \mathrm{~cm}>10 \mathrm{~cm}>15 \mathrm{~cm}>20 \mathrm{~cm}$. The heading stage and filling stage with jointing stage similar changes.

Above this change is closely related with the growth period the regularity of change of air temperature and the diurnal variation. Plastic film mulching on soil temperature increase at early growth stages of obvious effect, but in the late growth is not obvious, except with the outside temperature is related, on the other hand with the corn plant size and the amount of light the sun shine related ground, causes the soil heat conduction changes.

\subsection{The different weather conditions on the film drip maize soil temperature}

Under different weather types in different soil depth temperature changes are shown in Table 1. From Table 1, film mulching and no film mulching soil temperature difference significantly affected by weather conditions, regardless of sunny, cloudy, overcast sky, rainy (moderate), mulching in maize early growth stage regenerative have regenerative warming effect, can improve the temperature of the top layer of soil conditions. However, different weather conditions, the warming effect of different, namely: sunny day $>$ cloudy $>$ overcast sky>rainy day. The highest effect of temperature increase is sunny day: $5 \mathrm{~cm}\left(2^{\circ} \mathrm{C}\right), 10 \mathrm{~cm}$ $\left(2^{\circ} \mathrm{C}\right), 15 \mathrm{~cm}\left(1^{\circ} \mathrm{C}\right), 20 \mathrm{~cm}\left(-0.5^{\circ} \mathrm{C}\right)$; the effect of different soil layers temperature increase in cloudy is poor: $5 \mathrm{~cm}$ $\left(0.5^{\circ} \mathrm{C}\right), 10 \mathrm{~cm}\left(0.5^{\circ} \mathrm{C}\right), 15 \mathrm{~cm}\left(1.5^{\circ} \mathrm{C}\right), 20 \mathrm{~cm}\left(1.5^{\circ} \mathrm{C}\right)$; the lowest effect of temperature increase is rain day: $5 \mathrm{~cm}$ $\left(1{ }^{\circ} \mathrm{C}\right), 10 \mathrm{~cm}\left(0.5^{\circ} \mathrm{C}\right), 15 \mathrm{~cm}\left(0.5^{\circ} \mathrm{C}\right), 20 \mathrm{~cm}\left(0{ }^{\circ} \mathrm{C}\right)$.

Table 1: The determination of the value of covered and uncovered ground temperature under the different weather type 6 months late

\begin{tabular}{|c|c|c|c|c|c|c|c|c|c|c|c|c|}
\hline \multirow[b]{2}{*}{ Soil depth } & \multicolumn{3}{|c|}{ June 14 (Sunny day) } & \multicolumn{3}{|c|}{ June 23（Cloudy） } & \multicolumn{3}{|c|}{ June 24（Overcast sky） } & \multicolumn{3}{|c|}{ June 27（Moderate rain） } \\
\hline & Mul-ching & $\begin{array}{c}\text { No mul- } \\
\text { ching }\end{array}$ & Diffe-rence & Mul-ching & $\begin{array}{c}\text { No mul- } \\
\text { ching }\end{array}$ & Diffe-rence & Mul-ching & $\begin{array}{c}\text { No mul- } \\
\text { ching }\end{array}$ & Diffe-rence & Mul-ching & $\begin{array}{l}\text { No mu- } \\
\text { lching }\end{array}$ & Diffe-rence \\
\hline $5 \mathrm{~cm}$ & 26.5 & 24.5 & 2 & 26 & 24 & 2 & 22 & 21.5 & 0.5 & 23 & 22 & 1 \\
\hline $10 \mathrm{~cm}$ & 23 & 21 & 2 & 25.5 & 24.5 & 1 & 21.5 & 21 & 0.5 & 21.5 & 21 & 0.5 \\
\hline $15 \mathrm{~cm}$ & 22 & 21 & 1 & 25 & 24 & 1 & 22 & 20.5 & 1.5 & 21 & 20.5 & 0.5 \\
\hline $20 \mathrm{~cm}$ & 20.5 & 21 & -0.5 & 22.5 & 23 & -0.5 & 22 & 20.5 & 1.5 & 20.5 & 20.5 & 0 \\
\hline Average & 23.00 & 21.88 & 1.13 & 24.75 & 23.88 & 0.88 & 21.88 & 20.88 & 1.00 & 21.50 & 21.00 & 0.50 \\
\hline
\end{tabular}

Note: June 27 moderate rainfall of $21.4 \mathrm{~mm}$.

\section{Conclusions}

Temperature changes have a great impact on agricultural production. According to the research, agricultural production per area temperatures drop $1^{\circ} \mathrm{C}$, will reduce one week $(7 \mathrm{~d})$ of the growing season [20]. Mulching improves the early growth stage of corn daily average temperature, effectively increasing the soil temperature. Yongming Zhang [21] Studies have shown that mulching to increase in temperature has a significant effect, especially in the underground temperature at $5 \sim 15 \mathrm{~cm}$ influenced by mulching. The experimental results show that, in the diurnal variation of soil temperature the process, underground $5 \sim 10 \mathrm{~cm}$ soil has a rapid temperature rise and fall, temperature change is obvious, followed at $15 \mathrm{~cm}$ underground, underground at $20 \mathrm{~cm}$ is not too obvious, indicating the depth of the soil increases, the impact of mulch on soil temperature gradually decreased. Irrigation regulates soil temperature effects; the overall decline in irrigation soil temperature, shallow layer cooling is obvious. The Jiandong Wang, etc. [22] irrigation significantly delayed effects of temperature on temperature, consistent with a significant role in stabilizing temperature conclusion. Meanwhile $0 \sim 40 \mathrm{~cm}$ of soil temperature variation amplitude decreases, this is because the soil with high moisture content, high specific heat capacity.

Seedling, jointing stage soil temperature changes greatly with soil depth, heading and filling stage soil temperature of each layer little change. In the whole growth stages of maize, a sharp rise from seedling to jointing soil temperature and from the jointing stage to the filling stage the soil temperature decreased. As the

Weather warms, the seedling, jointing ground temperature significantly increased, seedling emergence at a maximum temperature of $20 \mathrm{~cm}$ soil layer, the lowest ground temperature occurs in $5 \mathrm{~cm}$ soil layer, while jointing the contrary, with a maximum temperature occurs in $5 \mathrm{~cm}$ soil layer, the lowest ground temperature at $20 \mathrm{~cm}$ soil layer appears, and the depth of each layer in the soil are film mulching ground temperature $>$ no film mulching. Heading and filling stage, the basic coverage of ground corn, made no direct sunlight ground, ground tem ${ }^{\circ} \mathrm{C}$ perature began to drop, but due to the overall ground temperature is relatively high, the surface temperature is still higher than the ground temperature, the maximum temperature occurs in $5 \mathrm{~cm}$ soil layer, the lowest ground temperature is $20 \mathrm{~cm}$ soil temperature, soil temperature difference but the depth of each layer in the soil is not very clear. The effect of temperature increase in the seedling to jointing stage soil warming fastest, heading $\sim$ filling stage warming effect difference.

The test in the analysis of irrigation on soil temperature is selected soil temperature typical irrigation date, can not fully reflect the relationship between irrigation and soil temperature, soil temperature increase can only show that there is an optimum irrigation quota and could not explain the irrigation quota soil temperature is conducive to optimum temperature for crop growth, it is necessary to define the optimum soil temperature corresponding irrigation quota in future studies. Currently Soil temperature variation of Chifeng region mostly study the 
impact farming methods, mulching on soil temperature changes and other measures, for the inter-relationship of irrigation and soil temperature, and research for the film bare crop irrigation is relatively weak, it is necessary to further relationship between soil temperature and coating drip irrigation amount of crops between the region and determine a reasonable irrigation quota, provide a theoretical basis for the film of water-saving irrigation crop production.

\section{Acknowledgements}

The research work was supported by National Natural Science Foundation of China under Grant No.51269018 and New four acres of water-saving irrigation projects and technology support projects of Inner Mongolia No.20121236.

\section{References}

[1] Xiaotang Hu, Mingsi Li. Effects of Drip Irrigation under cotton rhizosphere soil environment. China Eco-Agriculture, 2003.11 (3): 121-123. (In Chinese)

[2] Yongtao Zhang, Tianming Tang, Zengyin Li. Water Physiological effects of mulching. Soil and Water Conservation, 2001, 8 (3): 45-47. (In Chinese)

[3] Jingkuan Wang, Shunguo Liu, Shuangyi Li. On Soil inorganic nitrogen and nitrogen mineralization rates of long-term Mulching and Different Treatments. Soil and Water Conservation, 2006,20 (6): 107- 110. (In Chinese)

[4] Deqi Zhang, Yuncheng Liao, Zhikuan Jia. Arid Regions Research and mulching technology prospects. Agricultural Research, 2005, 23 (1): 208-213. (In Chinese)

[5] Xiangchun Xu, Chaoyun Wang. Domestic and mulching cultivation Present Situation and Prospects. Chinese hemp industry, 2006, 28 (1): 6-11. (In Chinese)

[6] Yi Li, Wenyan Wang, Qi Meng. Soil temperature field characteristics over a wide plastic covering. Agricultural Engineering, 2001, 17 (3): 32-36. (In Chinese)

[7] Yunqi Qian. Agricultural Meteorology. Xi'an: World Publishing Company, 1997. (In Chinese)

[8] Yajun Fan, Zhiyuan Lv, Delong Tian. Effect of different water film on the corn trait and ground temperature. Water Resources and Water Engineering, 2013, 24 (5): 152-156. (In Chinese)

[9] Wei Zhang, Xin Lv, Luhua Li. Xinjiang Cotton Drip Irrigation under salt migration law. Agricultural Engineering, 2008, 24 (8): 15-19. (In Chinese)

[10] Min Li, Yi Li, Wei Cao. Drip Irrigation under different scale grid of spatial variability of soil water and salt. Journal of Hydraulic Engineering, 2009, 40 (10): 1210-1218. (In Chinese)

[11] Rongtang Wang, Youning Wang, Xiurong Dong. Mulching cotton, corn, soybean growing stages cooling effect. Journal of Ecology, 2003, 23 (8): 16671672. (In Chinese)
[12] Huanjie Cai, Guangcheng Shao, Zhenhua Zhang. Experimental study of cotton under plastic mulch and irrigation water demand system. Journal of Hydraulic Engineering, 2002, 33 (11): 0119-0123. (In Chinese)

[13] Yi Li, Mingan Shao. Farmland temporal and spatial variation of crops covered ground temperature extremes. Journal of Applied Ecology, 2004, 15 (11): 2039-2044. (In Chinese)

[14] Henghong Chen, Shouxi Chai, Caixia Huang. Impact on dryland spring wheat mulching soil temperature. Gansu Agricultural University, 2013, 48 (1): 63-67. (In Chinese)

[15] Shengli Jin, Limin Zhou, Fengmin Li. Loess Plateau region of maize double ridge mulching soil temperature ditch sowing and planting techniques yield effect. Agricultural Research, 2010, 28 (2): 2833. (In Chinese)

[16] Zhifeng Jin. Effects of temperature change on northern soil water and salt transport law drip irrigation. Agricultural Research, 2014, 32 (2): 217 221. (In Chinese)

[17] Wang Xiaolin, Cheng Dongjuan, Gao ran. Research on Dynamic Change of Soil Temperature corn farmland film hole. Water-saving irrigation, 2012, (4): 19-21. (In Chinese)

[18] Xialing Xie, Yuanzhong Zhao. Drip Irrigation under variation of soil temperature of maize. Irrigation and Drainage, 2008, 27 (1): 90-92. (In Chinese)

[19] Yinchao Lan, Lixia Shen, Ruofan Li. Effects on soil temperature and moisture of different mulching. Chinese Agricultural Science Bulletin, 2013, 29 (12): 120-126. (In Chinese)

[20] Guojun Jiang, Zhenhua Wang, Xurong Zheng. Drip northern soybean cropping soil temperature field distribution. Northwestern Agricultural University, 2014, 23 (4): 45-51. (In Chinese)

[21] Yongming Zhang. Biodegradable mulching corn test. Gansu Agriculture, 2006 (1): 207-208. (In Chinese)

[22] Jiandong Wang, Shihong Gong, Yingduo Yu. Surface irrigation frequency on soil temperature and growth of spring maize. Hydraulic Engineering, 2008, 39 (4): 500-505. (In Chinese) 